CRORR 5(2014), 415-425

\title{
Project management in mine actions using Multi-Criteria- Analysis-based decision support system
}

\author{
Marko Mladineo ${ }^{1, *}$, Nenad Mladineo ${ }^{2}$ and Nikša Jajac $^{2}$ \\ ${ }^{1}$ Faculty of Electrical Engineering, Mechanical Engineering and Naval Architecture, \\ University of Split \\ Ruđera Boškovića 32, 21000 Split, Croatia \\ E-mail: 〈marko.mladineo@fesb.hr〉 \\ ${ }^{2}$ Faculty of Civil Engineering, Architecture and Geodesy, University of Split \\ Matice Hrvatske 15, 21000 Split, Croatia \\ E-mail: 〈\{mladineo, njajac\}@gradst.hr〉
}

\begin{abstract}
In this paper, a Web-based Decision Support System (Web DSS), that supports humanitarian demining operations and restoration of mine-contaminated areas, is presented. The financial shortage usually triggers a need for priority setting in Project Management in Mine actions. As part of the FP7 Project TIRAMISU, a specialized Web DSS has been developed to achieve a fully transparent priority setting process. It allows stakeholders and donors to actively join the decision making process using a user-friendly and intuitive Web application. The main advantage of this Web DSS is its unique way of managing a mine action project using Multi-Criteria Analysis (MCA), namely the PROMETHEE method, in order to select priorities for demining actions. The developed Web DSS allows decision makers to use several predefined scenarios (different criteria weights) or to develop their own, so it allows project managers to compare different demining possibilities with ease.
\end{abstract}

Key words: Decision Support System, Project Management, Multi-Criteria Analysis, PROMETHEE method, Geographic Information System

Received: September 17, 2014; accepted: December 30, 2014; available online: December 30, 2014

\section{Introduction}

Limited funds for humanitarian demining actions trigger a need for priority setting in Project Management in Mine actions. Multi-Criteria Analysis (MCA) has to be used in order to select priorities for demining actions. First of all, most of the MCA data (i.e., most of the criteria evaluations) are generated directly from the Geographic Information System (GIS). Second, MCA is performed using the PROMETHEE method, so criteria evaluations do not need to be

${ }^{*}$ Corresponding author. 
"converted" (i.e., one criterion can have the unit: square meters of area, the other criterion can have the unit: number of victims). Third, many different types of stakeholders can be included in assessment of criteria weights needed for the PROMETHEE method, so the results of MCA will be acceptable to everyone. All this, as part of the FP7 Project TIRAMISU, was integrated into a specialized Web DSS. It allows stakeholders and donors to actively join the decision making process using a user-friendly and intuitive Web application. All these advantages make this DSS very economical and efficient. Using this DSS, suspected minefields with highest priority will be demined first. That will decrease the number of new potential victims, and that will demine areas with highest potential of economic or social usage. Demining actions which are only "demining of the landscape" will have lowest priority. So, enormous potential economic growth and social welfare can be achieved using this DSS. The developed Web DSS allows decision makers to use several predefined scenarios for priority setting and it allows easy inclusion of several stakeholders in the decision process.

\section{State-of-the-art}

In Croatia, over the past ten years, priority setting using Multi-Criteria Analysis (MCA) coupled with GIS has been deployed in mine-action management [7, 9]. A multi-criteria approach gives an opportunity for stakeholders to express their needs and requirements through a set of criteria [6]. Therefore, the methodology provides full transparency of decision data [1] visible to all stakeholders, so that anyone who is either directly involved in the Mine Action process or affected by landmines could follow the process. Priority setting [10] should be used to ensure that the limited resources of a mine action programme can have the greatest possible impact in each planning cycle on the socio-economic blockages caused by landmines. The application of MCA tools to the decision making process has been widely recognised [3] for its utility in offering fundamental help for the decision maker in the presence of possibly conflicting targets [4].

While using MCA, two problems have been noticed. The first one refers to the size and scope of either minefields or mine suspected areas, so they could be mutually comparable. A result from the comparison process is priority rank for mine clearance. Each minefield is an action in MCA having its own rank in relation to defined criteria. The second problem relates to the fact that each decision level demands a different criteria set, as well as to the fact that a demining process on different land cover areas (water, woodlands, etc.) needs distinctive criteria. Experience in the application of MCA resulted in a GIS- 
based Decision Support System (DSS) which comprehends different decision levels and land cover areas.

Furthermore, a DSS presented in [5] and [9] does not have a user-friendly interface which would allow stakeholders and donors to actively join the decision making process. Additionally, the DSS interface should be accessible over the Web as a web application.

\section{Methodology}

\subsection{Project management based on a decision support system}

For successful management of Mine action projects, one of the most important things is setting of humanitarian demining priorities [5]. It requires development of a specific decision-making process, i.e., development of a specific Decision Support System (DSS). Such a DSS can support the needs for different approaches at different decision levels, thus modelling the decision process in the most appropriate way. As a result of the problematic characteristics of mine action, a multi-level approach is developed: for each problem level, a specific procedure for criteria and action (solution) evaluation is developed (Figure 1). This means that a separate 'set of actions' is developed at each decision level (projects for humanitarian demining of sociopolitical entities, such as counties, municipalities, villages, minefields, homogenous areas, etc.). Such sets are created by the GIS, and evaluated by applying multi-criteria analysis. Each particular 'set of actions' is created according to territorial aspects and the political organization of the country in question. Therefore, three basic levels should be recognized in mapping the DSS structure [8].

When of strategic nature, problems should be treated at the state level; consequently, counties, regions, or districts form a logical set of actions evaluated by multi-criteria analysis. Alternatively, at the state level, homogenous zones can equally be defined as a set of actions. In this context, 'homogenous zones' are defined as parts of territories with common characteristics, for example: unique agriculture areas or forests or rural areas with domestic backyards, etc. Actions are ranked according to humanitarian demining priorities, which stem from assessment of the primary assets of the country (energy production zones, water supply zones, transportation and other infrastructure, ecologically valuable areas, tourism, fire-endangered areas, areas that are under special state auspices, etc.). 


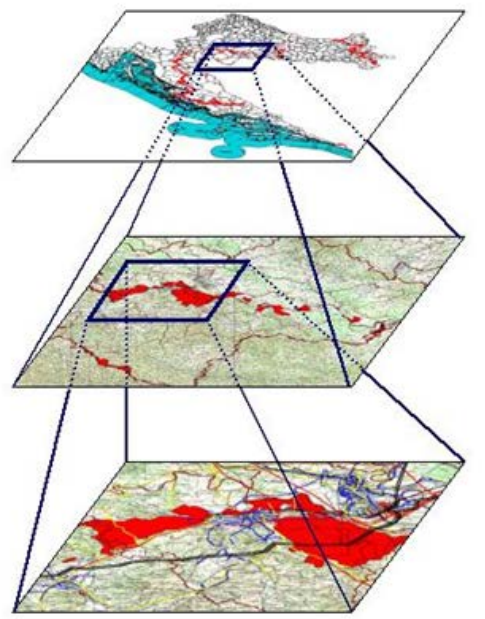

Strategic level

- state level

Tactical level

- county level

Operative level

- municipality level

Figure 1: Layout of the hierarchical approach in decision-making

At the tactical level, the problem should be treated at a lower territorial and socio-political level, such as the levels of county, region, and district, so municipalities, communities or larger city areas make up a logical set of actions. Alternatively, at this level, homogenous zones can be defined as a set of actions which are ranked according to humanitarian demining priorities related to the basic orientations of counties, regions or districts. Generally, at this level, homogenous zones can be defined according to the criteria that concern:

- terrain characteristics (slope, accessibility, etc.), and suspected minefield characteristics (mine density, risk degree, information reliability, mine types, etc.);

- social parameters, such as demographic data (population structure, nationality, family structure, etc.);

- economic parameters (basic economic mainstay of population, employment, average income, potential of the area, expected positive effect after humanitarian demining, etc.);

- political parameters, such as direct intervention from the state level or donors (return of refuges, areas under special state auspices, boundary areas, etc.);

- legislative parameters (property structure, general purpose of the area, etc.).

At the operational level, problems should be treated with respect to humanitarian demining projects, minefields, selection of a humanitarian demining company and technological support, etc. 
According to this stratification, a particular 'criteria set' for each multicriteria evaluation has to be developed. However, for each decision level, a team of experts has to make the criteria set more detailed, by co-coordinating it with the demands characteristic of that particular level, as well as with 'partners' in the decision process.

The strategic decision level is the macro-approach (using macroeconomic and other global parameters) to coordinate strategic partners: government, competent ministries and international organizations.

The tactical level is the approach which takes account of the parameters most important for development of a particular region, as well as parameters important for political stability and/or satisfaction of the local population (comprehensible and global criteria that apprehend personal interests of each inhabitant, especially in areas where there is a possibility of national conflicts, or a conflict caused by the ratio of resident and incoming inhabitants, etc.). At the tactical level, the partners included in the discussion about criteria are, firstly, socio-political organizations of counties, refugees' associations, and important infrastructure systems such as public corporations (waterworks, electro-works, telecommunications, big agricultural systems, etc.). At this level, various donors can also participate in discussions as partners.

Operational decisions are taken at the micro-approach level, related to the technical and technological aspects of a particular mine action, as well as economic parameters in the valorization of each project or demining company. At the operative level, the partners in the decision process are municipal organizations, corporations, demining companies' delegations, etc.

The hierarchical approach is very useful because, at the strategic level, it makes distribution of money for humanitarian demining of mine-affected counties easier by simulating results attained from multi-criteria analysis. At the tactical level, the county distributes finances to the endangered municipalities or similar entities, again based on multi-criteria analysis. At the operative level, the municipality distributes approved funds to particular projects, for the use of communities or infrastructure, based on its own criteria and the results of the Multi-Criteria Analysis (MCA). Therefore, there is a need to use a proper MCA method, and in this paper the PROMETHEE method was chosen.

\subsection{PROMETHEE method}

The PROMETHEE method was developed by J. P. Brans and B. Mareschal in 1983 [2]. Today, it is well accepted by decision-makers because it is comprehensive and has the ability to present results using simple ranking [2]. An input for the PROMETHEE method is a matrix consisting of a set of 
potential alternatives (actions) $A$, where each $a$ element of $A$ has its $f(a)$ which represents evaluation of one criterion. Each evaluation $f_{j}\left(a_{i}\right)$ must be a real number. The method PROMETHEE I ranks actions by partial ranking, with the following dominance flows, for the positive outranking flow [2]:

$$
\Phi^{+}(a)=\frac{1}{n-1} \sum_{x \in A} \Pi(a, x)
$$

and for the negative outranking flow [2]:

$$
\Phi^{-}(a)=\frac{1}{n-1} \sum_{x \in A} \Pi(x, a),
$$

where $a$ and $x$ represent the actions from the set of action $A$ (during the pairwise comparison of action $a$ with all other $n$ - 1 actions), $n$ is the number of actions and $\Pi$ is the aggregated preference index defined for each couple of actions.

The PROMETHEE I method gives the partial relation, and then a net outranking flow is obtained from the PROMETHEE II method which ranks the actions by the complete ranking calculating net flow [2]:

$$
\Phi(a)=\Phi^{+}(a)-\Phi^{-}(a),
$$

In the sense of priority assessment, the net outranking flow represents the synthetic parameter based on defined criteria and priorities among criteria. Usually, criteria are weighted using criteria weights $w_{j}$ and a usual pondering technique:

$$
\Pi(a, b)=\frac{\sum_{j=1}^{m} w_{j} P_{j}(a, b)}{\sum_{j=1}^{m} w_{j}},
$$

where $P_{j}(a, b)$ represents preference of $a$ over $b$ for a given preference function of criterion $j$. There are six types of preference functions proposed by authors of the method [2] presented in the following table (Table 1) where parameter $q$ represents the indifference threshold, parameter $p$ represents preference thresholds and parameter $\sigma$ represents the Gaussian threshold. 
Project management in mine actions using Multi-Criteria-Analysis-based decision

support system

\begin{tabular}{|l|l|c|}
\hline \multicolumn{1}{|c|}{ Preference function } & \multicolumn{1}{|c|}{ Definition } & Parameters \\
\hline Usual & $P(d)= \begin{cases}0, & d=0 \\
1, & d \neq 0\end{cases}$ & - \\
\hline U-shape & $P(d)=\left\{\begin{array}{ll|}0, & |d|<q \\
1, & |d| \geq q\end{array}\right.$ & $q$ \\
\hline V-shape & $P(d)= \begin{cases}\frac{d \mid}{p}, & |d|<p \\
1, & |d| \geq p\end{cases}$ \\
\hline Level & $P(d)=\left\{\begin{array}{cc}0, & |d|<q \\
0.5, & q<|d|<p \\
1, & |d|>p\end{array}\right.$ \\
\hline V-Shape with indifference & $P(d)=\left\{\begin{array}{cc}0, & |d|<q \\
|d|-q & q<q \\
1, & |d|>p\end{array}\right.$ \\
\hline Gaussian & $P(d)=1-e^{-\frac{d^{2}}{2 \sigma^{2}}}$ & $q, p$ \\
\hline
\end{tabular}

Table 1: Types of preference functions

Furthermore, different sets of criteria weights can be used and then each set represents one scenario. Criteria weights are usually determined by experts and sometimes other stakeholders are taken into account. In case of many different stakeholders and many different views on each weight, an average value of each weight is calculated.

\section{Results}

Since several stakeholders, usually dislocated, are included in the priority setting process, the main disadvantage of developed Decision Support Systems [5, 8, 9] was that they are just local, i.e., not on the Web. Therefore, a new Web-based Decision Support System (Web DSS) has been developed as a web application. It couples GIS thematic layers and MCA making it accessible via a user-friendly interface to different stakeholders. Consequently, priority setting has become fully transparent since stakeholders and donors are able to actively join the decision making process using an on-line web application. The stakeholders and donors were also included in criteria weights setting. Criteria weights determined by them were used to calculate aggregate weight for each criterion. 
In the developed Web DSS, a case study of priority setting in SisakMoslavina County in Croatia is used to present the developed approach. There are 24 criteria grouped into four groups:

- Impact of terrain characteristics and infrastructure: roads MSA (Mine Suspected Area), rivers MSA, low electric power lines MSA, water pipes MSA, telecommunication lines MSA, high electric power lines MSA, gas pipes MSA, oil pipes MSA, rails MSA, anti-floods MSA, fire brigade paths MSA;

- Economic impact of mine clearance: houses MSA, soils MSA, expected employments, touristic MSA, hunting MSA;

- Social welfare impact: expected return of population, national parks MSA, nature parks MSA, near border MSA, forests MSA;

- Impact of land-mine risk reduction: area of mine suspected polygon, number of mines, number of mine victims.

For each criterion, each municipality made evaluation for each mine suspected polygon in that municipality. An example of evaluation for some criteria for 11 municipalities is presented in the following table (Table 2).

\begin{tabular}{|c|c|c|c|c|c|c|c|}
\hline Municipality & $\begin{array}{l}\text { Expected } \\
\text { return of } \\
\text { population }\end{array}$ & $\begin{array}{c}\text { Houses } \\
\text { MSA }\end{array}$ & $\begin{array}{l}\text { Roads } \\
\text { MSA }\end{array}$ & $\begin{array}{l}\text { Soils } \\
\text { MSA }\end{array}$ & $\begin{array}{c}\text { Area of } \\
\text { mine } \\
\text { suspected } \\
\text { polygon }\end{array}$ & $\begin{array}{l}\text { Number } \\
\text { of mines }\end{array}$ & $\begin{array}{l}\text { Number } \\
\text { of mines } \\
\text { victims }\end{array}$ \\
\hline & number & $\mathrm{m}^{2}$ & $\mathrm{~m}^{2}$ & $\mathrm{~m}^{2}$ & $\mathrm{~m}^{2}$ & number & number \\
\hline Dvor & 70 & 6021000 & 5000 & 771000 & 62075180 & 1882 & 2 \\
\hline Glina & 1905 & 49000 & 23000 & 9100000 & 22961101 & 775 & 9 \\
\hline Gvozd & 0 & 0 & 0 & 200000 & 439870 & 93 & 0 \\
\hline Hrv. Dubica & 0 & 0 & 4400 & 2400000 & 6943000 & 465 & 0 \\
\hline $\begin{array}{l}\text { Hrv. } \\
\text { Kostajnica }\end{array}$ & 15 & 10000 & 300 & 500000 & 580500 & 61 & 0 \\
\hline Jasenovac & 22 & 83000 & 32022 & 4520000 & 11919650 & 4795 & 1 \\
\hline Novska & 0 & 600000 & 5400 & 2752000 & 10749500 & 5809 & 0 \\
\hline Petrinja & 1066 & 1952000 & 43500 & 36502000 & 72850261 & 28060 & 33 \\
\hline Sisak & 50 & 1700000 & 10000 & 14140000 & 21332050 & 1625 & 2 \\
\hline Sunja & 1100 & 2194000 & 21000 & 29838000 & 38996801 & 3111 & 11 \\
\hline Topusko & 100 & 225000 & 3500 & 152500 & 1968000 & 88 & 2 \\
\hline
\end{tabular}

Table 2: Evaluations of some criteria for 11 municipalities

Figures 2 and 3 show an example of priority setting in Sisak-Moslavina County. Weights of criteria groups could be easily changed on-line with automatic update of MCA results. The results of Multi-Criteria Analysis (MCA) are displayed in multiple ways: on a chart that represents the PROMETHEE II output, on a map by placing a rank number on each suspected minefield, and on a suspected minefield's "map tip" with details about each suspected minefield's rank. 


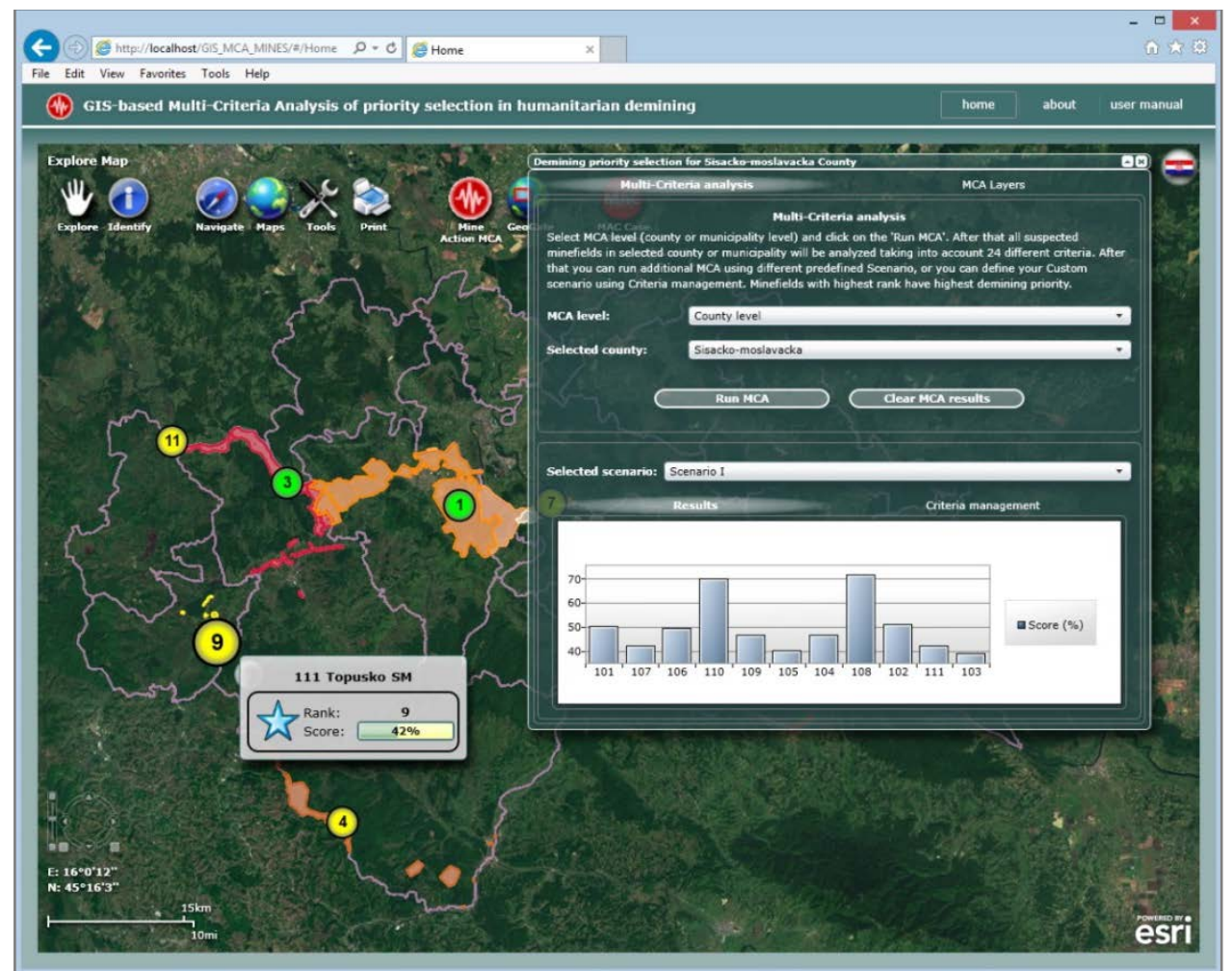

Figure 2: Display of results of Multi-Criteria Analysis for criteria weights predefined by "Scenario I" on a county level

By scenario selection, a decision stakeholder attitude is transferred into MCA. In Figure 2, a predefined "Scenario I" is used, in which criteria groups "Social welfare" and "Economic impact of mine clearance" have highest weights. In Figure 3, a "Custom scenario" is used, in which criteria group "Impact of terrain characteristics and infrastructure" has the highest weight. A change of criteria weights affected ranks.

Furthermore, in Figure 2 and 3, an MCA is performed on a county level (tactical level), but it can also be performed on a municipality level (operative level) or a state level (strategic level). In that way, complete management of mine action projects is available on-line to project managers (http://tiramisu.maps.arcgis.com).

In this Sisak-Moslavina County case study, a linear (V-shape with indifference) preference function type was used for each criterion. Furthermore, criteria weights were determined by stakeholders and donors, as already mentioned. 


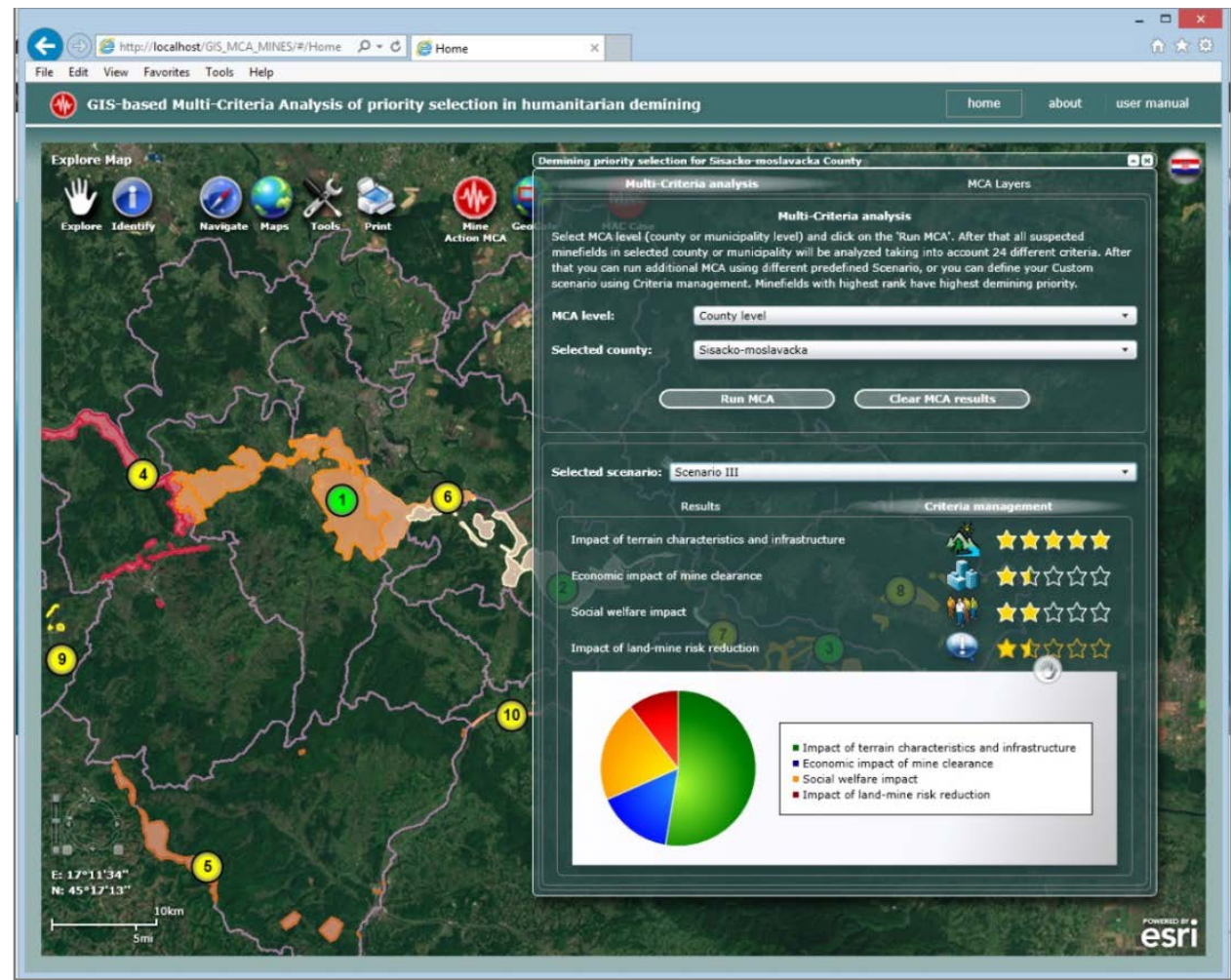

Figure 3: Display of results of Multi-Criteria Analysis for custom defined criteria weights ("Custom scenario") on a county level

\section{Conclusion}

Mine action project management often deals with limited funds, and thus requires efficient tools for the establishment of mine clearance priorities. Between "small" farmers, whose backyards are contaminated, and county and community councils, forums and representatives, there are several levels that are directly or indirectly exposed to mine accident risks. All of them, more or less, expect that their problem should be treated as priority 1, so their involvement in the decision-making process lowers tensions and significantly reduces frustrations that may result from the prolongation of the problem solving process. This paper demonstrated how to easily include several stakeholders in the decision-making process of priority selection in humanitarian demining. A new web-based Decision Support System (Web DSS) has been developed as a web application. It couples GIS thematic layers and MCA (PROMETHEE method) via a user-friendly interface achieving priority setting to become fully transparent. A case study of demining priority setting for Sisak-Moslavina 
County in Croatia is presented in a developed web-based DSS; however, the same or similar approach can be applied in other countries. Some basic GIS thematic layers for Cambodia are placed in a web-based DSS and they can be used to define criteria for demining priority setting in Cambodia. Further research will be based on defining more predefined scenarios and criteria weights sensitivity analysis.

\section{References}

[1] Benini, A.A., Conley, C.E., Shdeed, R., Spurway, K. And Yarmoshuk, M. (2003). Integration of different data bodies for humanitarian decision support: An example from mine action. Disasters, 27, 288-304.

[2] Brans, J.P., Mareschal, B., Vincke, P.H. (1984). PROMETHEE - a new family of outranking methods in multicriteria analysis. Operational Research IFORS 84, Amsterdam.

[3] De Leeneer, I., Pastijn, H. (2002). Selecting land mine detection strategies by means of outranking MCDM techniques. European Journal of Operational Research, 139, $327-338$

[4] Jankowski, P. (1995). Integrating geographical information systems and multiple criteria decision-making methods. International Journal of Geographic Information Systems, 9, 251-273.

[5] Knezic, S., Mladineo, N. (2006). GIS - based DSS for priority setting in humanitarian mine - action. International Journal of Geographical Information Science, 20, 5, 565-588.

[6] Krtalic, A. (2012). Levels of data within Advanced Intelligence Decision Support System (AI DSS). 9th Symposium Humanitarian Demining 2012, Sibenik.

[7] Matic, C., Laura, D., Tursic, R., Krtalic, A. (2014). Analytical assessment for the process of collecting additional data on a suspected hazardous area in humanitarian demining. CROMAC-CTDT Ltd., Zagreb.

[8] Mladineo, N. Knezic, S. (2003). Decision support system for demining waterways. Journal of Mine Action, 7,3 .

[9] Mladineo, N., Knezic, S. Gorseta, D. (2003). Hierarchic approach to mine action in Croatia. Journal of Mine Action, 7, 2, 41-45.

[10] Van der Merwe, J. (2003). Priority setting for mine action. Journal of Mine Action, 7,3 . 